Purdue University Purdue e-Pubs

10-29-2009

\title{
Inverse Characterization of Poro-Elastic Materials Based on Acoustical Input Data
}

J Stuart Bolton

Purdue University, bolton@purdue.edu

Kwanwoo Hong

Follow this and additional works at: http:/ / docs.lib.purdue.edu/herrick

Bolton, J Stuart and Hong, Kwanwoo, "Inverse Characterization of Poro-Elastic Materials Based on Acoustical Input Data" (2009). Publications of the Ray W. Herrick Laboratories. Paper 30.

http://docs.lib.purdue.edu/herrick/30

This document has been made available through Purdue e-Pubs, a service of the Purdue University Libraries. Please contact epubs@purdue.edu for additional information. 


\section{Inverse Characterization of Poro-Elastic Materials based on Acoustical Input Data}

J. Stuart Bolton and Kwanwoo Hong

Ray W. Herrick Laboratories

School of Mechanical Engineering

Purdue University

ASA San Antonio - 29 October 2009 


\section{Introduction}

- Brief history of standing wave tube

- Four-microphone standing wave tube

- Estimation of Biot parameters based on acoustical measurements 


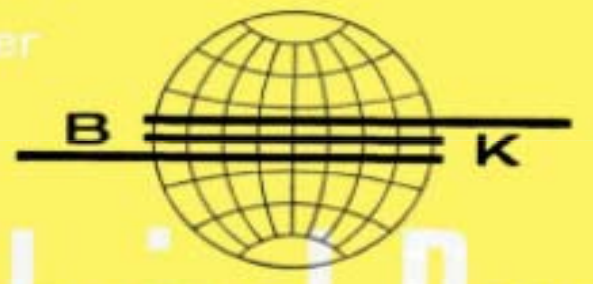

Teletechnical, Acoustical and Vibrational Research

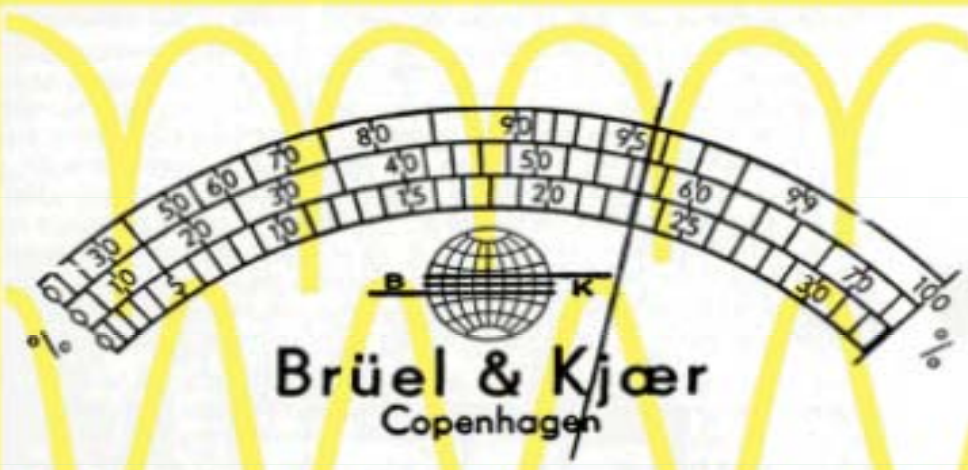

STANDING WAVE

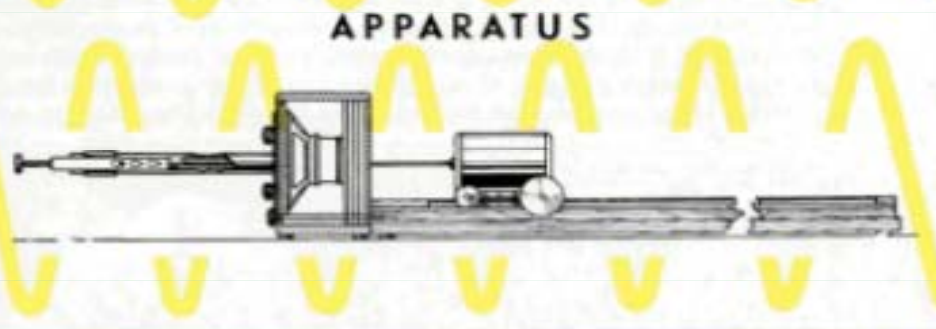

No. 1

January 1955 

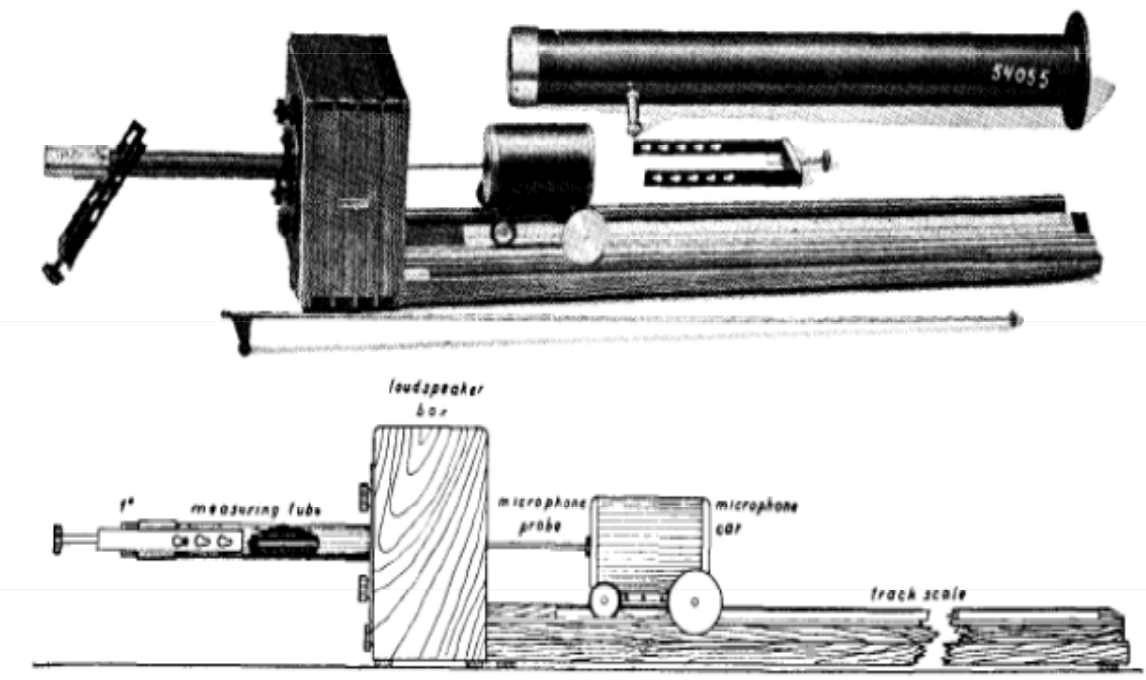

loudspeoker
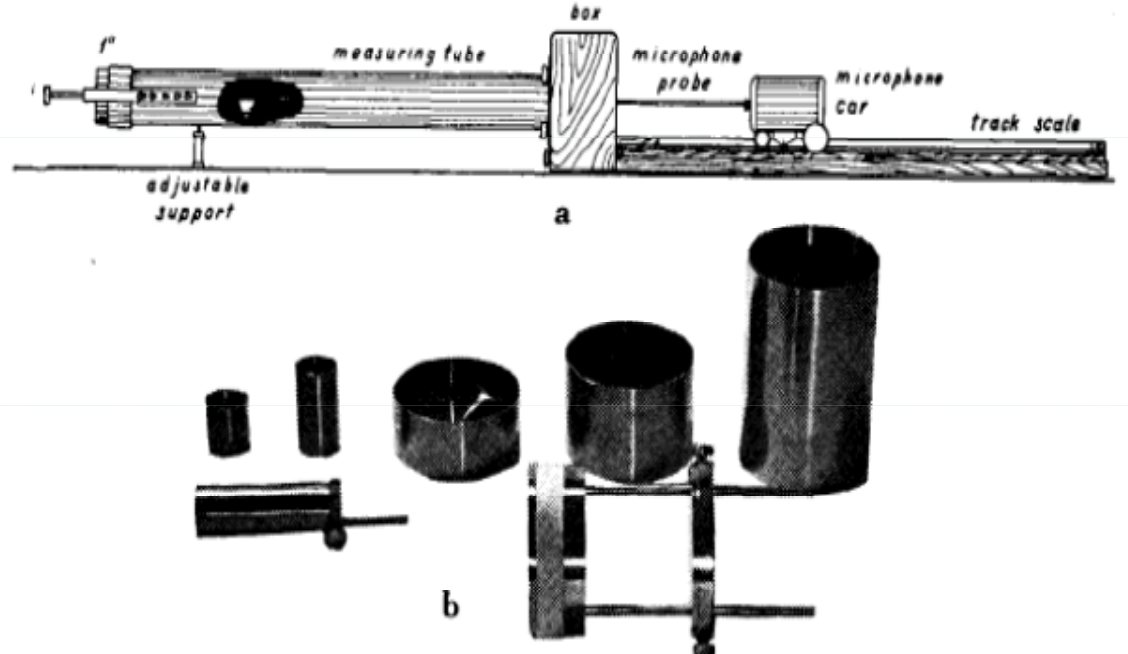

Fig. 3. a) Photograph and drawings of the Standing Wave Apparatus type 4002. b) Photograph of the six different sample holders belonging to the apparatus. 


\section{Standing Wave Tube}

- Standing wave method for measuring normal incidence absorption coefficients more than 100 years old

- Method is credited by a number of authors to $\mathrm{J}$.

Tuma (1902)

- Subsequent experiments conducted by Weisbach (1910) and Taylor (1913) 
upper limit of audibility, showing that the apparatus is applicable to any probable range of pitch.

The different parts of the apparatus used for making observations for sound absorption have already been described. The parts were assembled as shown in Fig. 14. The flue, $F$, moved along a graduated

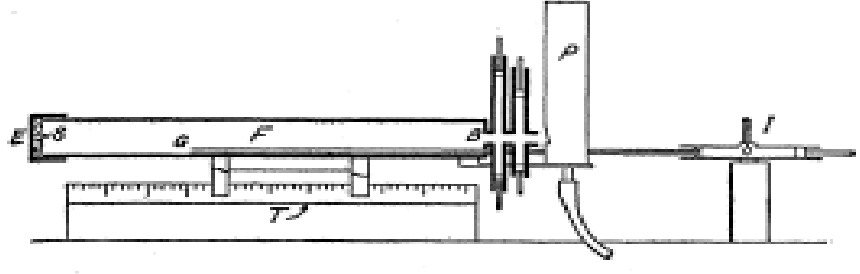

Fig. 14.

\section{A DIRECT METHOD OF FINDING THE VALUE OF MATERIALS AS SOUND ABSORBERS.}

By HAWLEY O. TAYLOR. track, $T$. The one-half-inch glass tube, $I G$, from the suspended disc passed through the tone screen at $B$ and projected into the flue. The intensity of sound at the end, $G$, of this tube causes the air in the tube to vibrate and this in turn produces a deflection of the disc.

In taking observations, the flue, $F$, with the organ pipe, $P$, attached to it was moved along the track, $T$, in steps one centimeter long. Observations for intensity were made at each step, and at the region of maximum and minimum intensities for shorter steps, and thus the maximum and minimum intensities, $m$ and $n$ of the formula, were found. Applying these values in the formula, the coefficient of absorption of sound for the material, $S$, closing the end, $E$, of the flue, $F$, was calculated as already shown by an example.

Following is the coefficient of absorption of a few materials computed by using the approximate formula:

\begin{tabular}{|c|c|c|c|}
\hline Material. & $m$ & * & $=$ \\
\hline Smyrna Rug. & 6.55 & .04 & .26 \\
\hline Brussels Carpet ......... & 7.30 & .03 & .23 \\
\hline Hair felt (1-inch thick)... & 24.70 & .78 & .51 \\
\hline Ceilinite (A-inch thick). & 57.50 & .22 & .25 \\
\hline Asbestos roll fire felt ( 2 -inch thick). & 54.50 & .30 & .26 \\
\hline Compressed cork (13-inch thick).......... & 27.00 & .25 & .32 \\
\hline
\end{tabular}

The last four materials were kindly furnished by the Johns-Manville Co. of New York. The values of the absorbing power given here for the first three materials check fairly well with values obtained by the reverberation method.

The absorbing power of material is increased by increasing the space 


\title{
Some Notes on the Measurement of Acoustic Impedance
}

\author{
LEO L. BERANEK* \\ Cruft Laboratory, Harvard University, Cambridge, Massachusetts
}

(Received March 4, 1947)

A modified form of an earlier design of impedance tube is described here. It is capable of measuring the normal impedance of a sample by the variable length, variable frequency, or traveling microphone methods without disturbing the sample in transferring from one test method to another. The tube also may be used to measure the transmission constant with the aid of a long probe tube. Modern graphical aids to the calculation of the impedance from the quantities measured in the tube are described. Comparison of data obtained by the variable length and traveling microphone methods is made, and good agreement is found over most of the frequency range. It is shown that the clamping effects of the tube walls on the edge of a lightweight, non-rigid sample are serious enough to introduce large gyrations of the impedance curves at frequencies below 500 c.p.s.

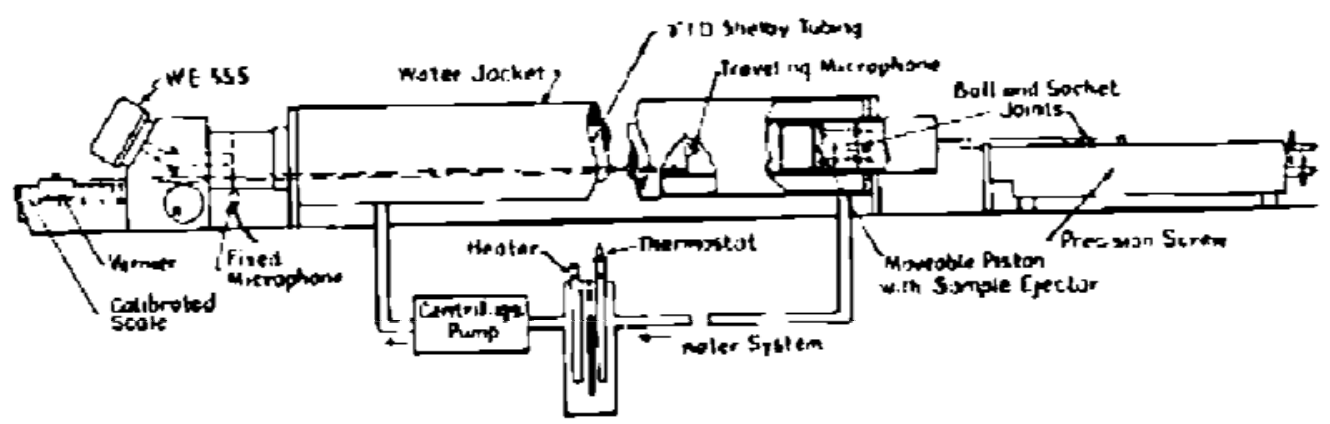

Fic. 1. Sketch of the impordance measuring tube. The soale is cali'mated in millineters or terths of inches. The precision ocriw muy le remkverl to per:nit at tarhing a secund piere of Shcthy tubing Cuntaining a ifeep sample of material. A high impedance air leak is provided at the luudspaker end to relieve static pressures. Uther details are given in the text. 


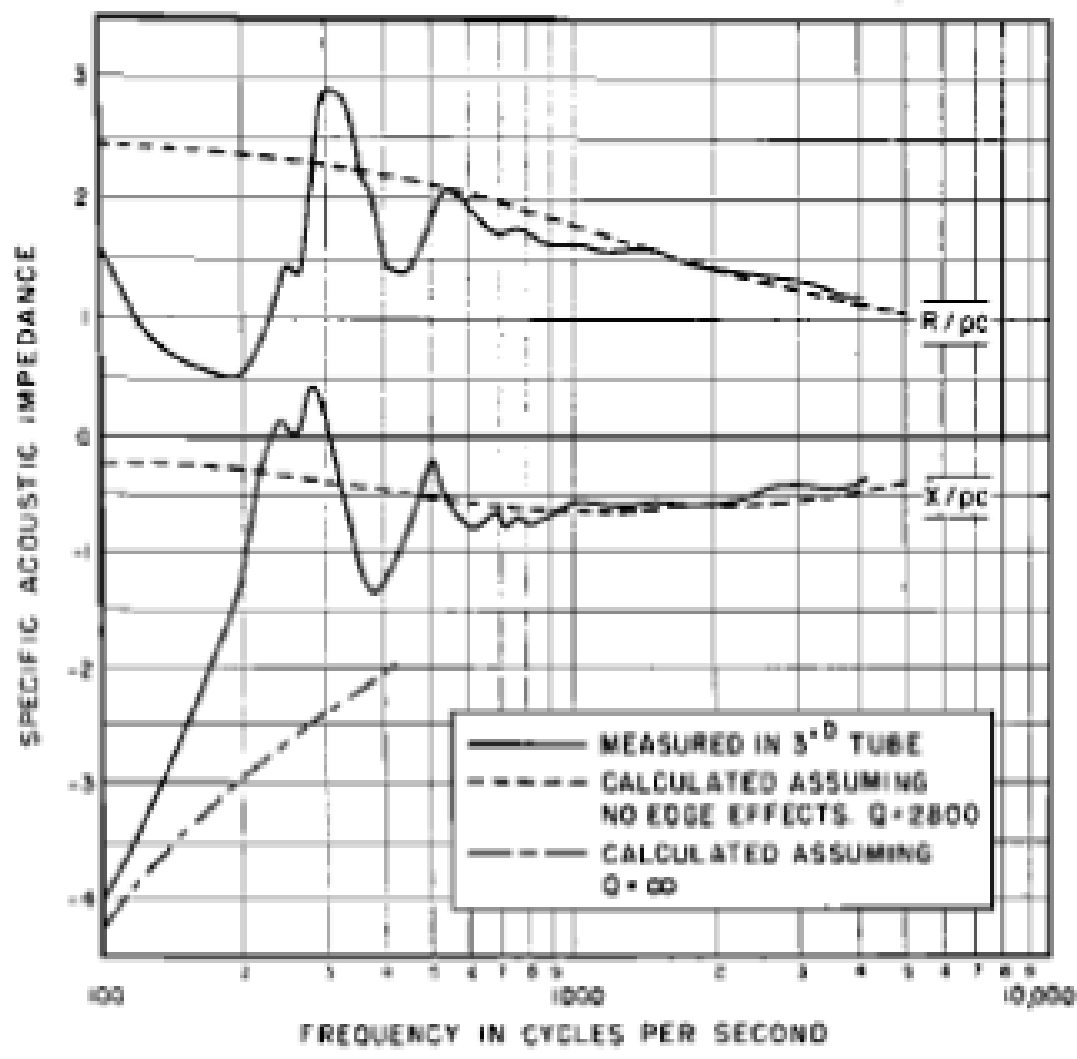

Fig. 9. Measured es. calculated impedance curves for a very light weight sample of porous absorbing blanket. The effect of the clamping of the tube on the edges of the sample at low frequencies is clearly shown. $Q$ is the volume coefficient of elasticity of the sample in dynes $/ \mathrm{cm}^{2}$.
A number of materials were studied for the purpose of determining the effect of the restraining action of the three-inch diameter tube on the edge of the sample. A typical set of data for a five foot deep sample of material having a volume density of $0.00754 \mathrm{~g} / \mathrm{cm}^{2}$, a specific flow resistance of 34.4 acoustic ohms per centimeter of thickness $\left(\mathrm{g} \mathrm{cm}^{-3} \mathrm{sec}^{-1}\right)$, a porosity of 0.996 , and a volume coefficient of elasticity, $Q$, of $2800 \mathrm{dyne} / \mathrm{cm}^{2}$, is shown in Fig. 9. Calculated curves of $R / \rho c$ and $X / \rho c$ for this sample are shown by the dashed lines. It is apparent that the calculated and measured curves differ significantly at frequencies below 500 c.p.s. The theory did not take into account the restraining action of the sidewalls of the tube on the edge of the sample. In order

to take this restraining action into account, each successive layer of material must be treated as a clamped-edge diaphragm. No simple theory now exists for calculating in detail the impedance of a clamped-edge, dissipative diaphragm, but it is easy to see that it will resonate at certain frequencies and that at very low frequencies its reactance will become negative and large. The dash-dot line at the bottom left edge of Fig. 9 was calculated assuming that the material had 


\section{Brüel \& Kjœr

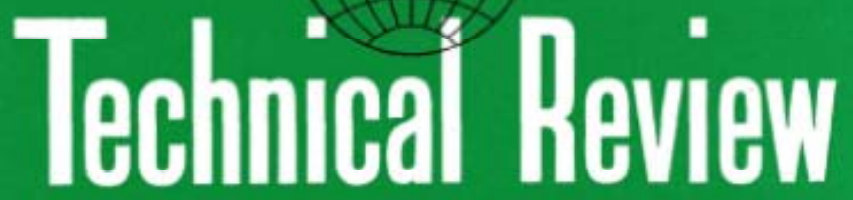

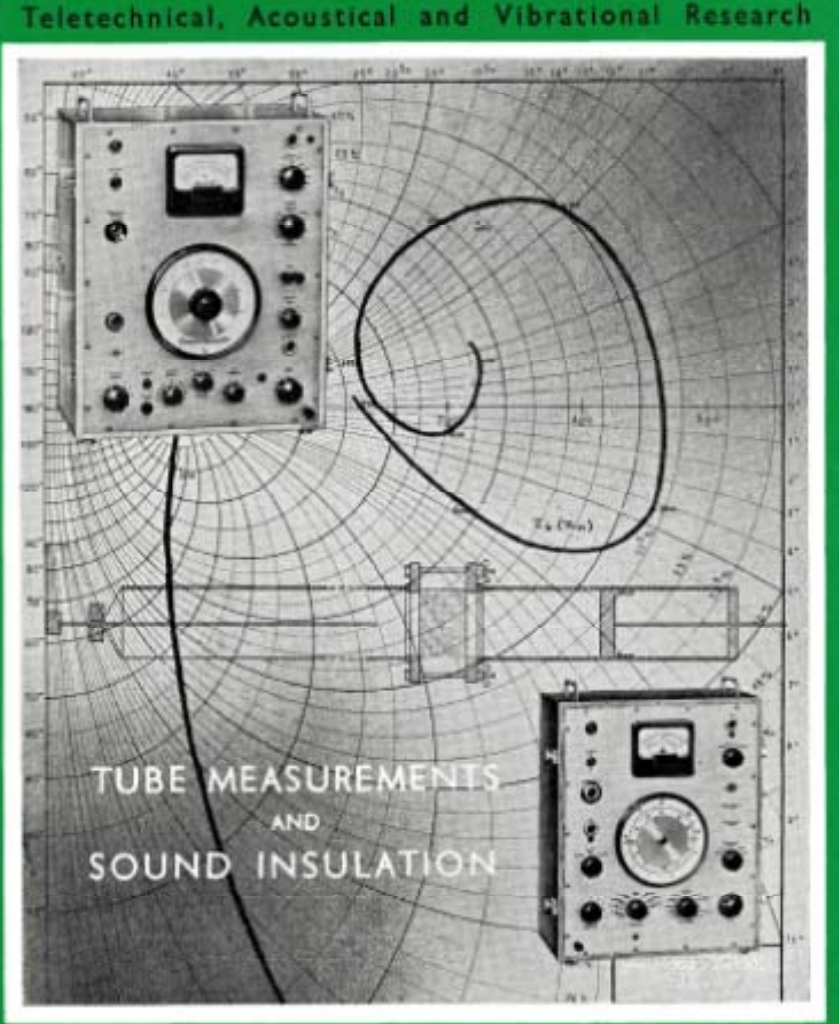

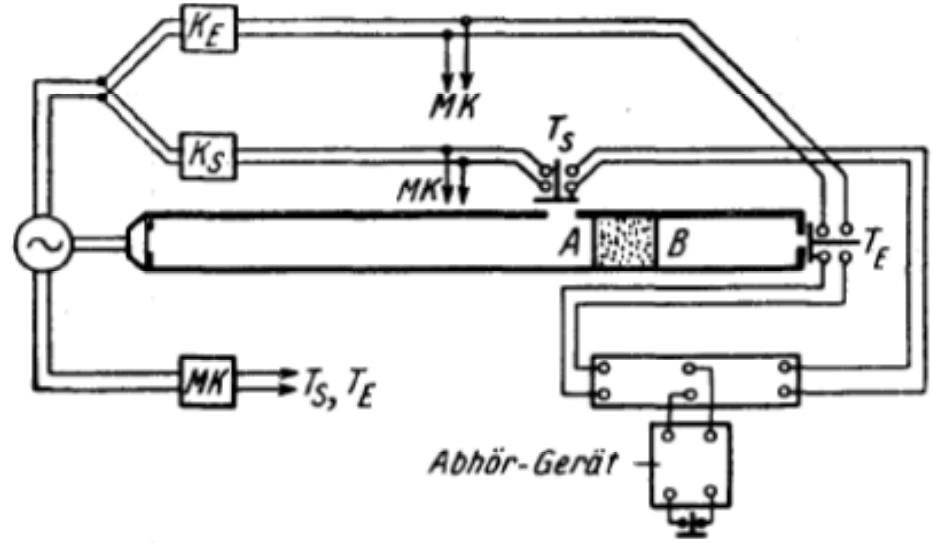

Fig. 5. Determination of the coefficients of an acoustical four-terminal network by means of a tube measurement and compensation microphones according to $\left.W u ̈ s t^{3}\right)$.

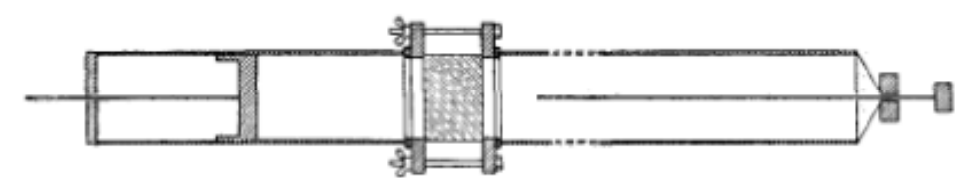

Fig. 6. Impedance measurements on test sample, with normal standing wave measurement. The conditions "open and short circuited quadripole" are fulfilled by placing the piston in the cylinder close to the sample and at a distance of $1 / 4$ wave length $\lambda$. 


\section{Measurement of the characteristic impedance and propagation constant of materials having high flow resistivity}

Yvan Champoux $x^{a}$ and Michael R. Stinson

Institute for Microstructural Sciences, National Research Council, Ottawa, Ontario K1A OR6, Canada

(Received 20 November 1990; accepted for publication 8 May 1991)

A technique for the measurement of characteristic acoustical impedance and propagation constant of porous materials is presented. Samples are mounted in an impedance tube and both the surface impedance and a transfer function along the sample length are determined; characteristic impedance and propagation constant may be calculated using these quantities. For this implementation, a classical standing wave procedure is used for the determination of surface impedance. Measurements are obtained for frequencies between 100 and $4000 \mathrm{~Hz}$. A special procedure that makes use of extension tubes, between sample and the fixed part of the impedance tube, is used to achieve the low-frequency results. The new technique yields results that are comparable in accuracy to the "two-cavity" technique described by Utsuno et al. [J. Acoust. Soc. Am. 86, 637-643 (1989)] for samples of low flow resistivity (17.2 and 43.6 cgsrayl $\mathrm{cm}^{-1}$ ), but substantially better for a sample of higher flow resistivity ( $380 \mathrm{cgs}-$-rayl $\mathrm{cm}^{-1}$ ).

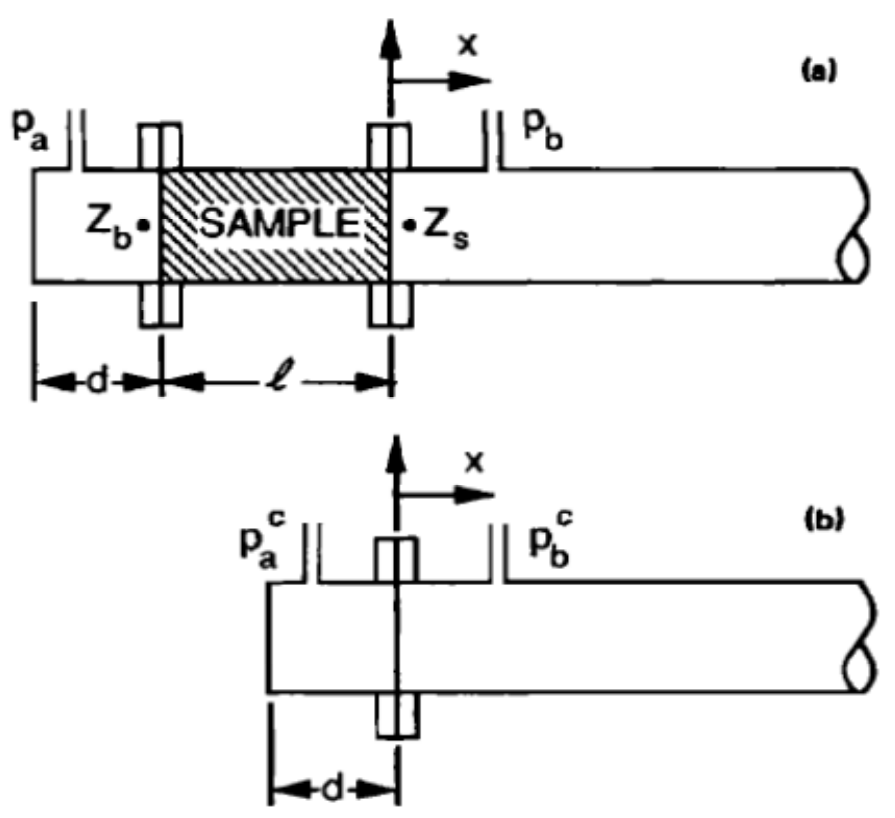

FIG. 1. Sketch of the sample end of the measurement tube, showing the principle of operation of the measurement technique. In panel (a), measurement of the impedance $Z$, at the surface of the sample $(x=0)$ and the transfer function between microphones at $x_{a}$ and $x_{h}$ allows the material to be characterized acoustically. The microphones are calibrated against each other by removing the sample, as in (b). 


\section{Four Microphone Method}

- Four-microphone tube for silencer testing

- Munjal (Duct Acoustics)

- Two-load method

- Two-source method

- Four-microphone tube for material testing

- Suggested by Joseph Pope

- Yun and Bolton (1997 SAE)

- Song and Bolton (2000 JASA) introduce transfer matrix approach

- Many articles since then 


\section{Transfer Matrix Method}

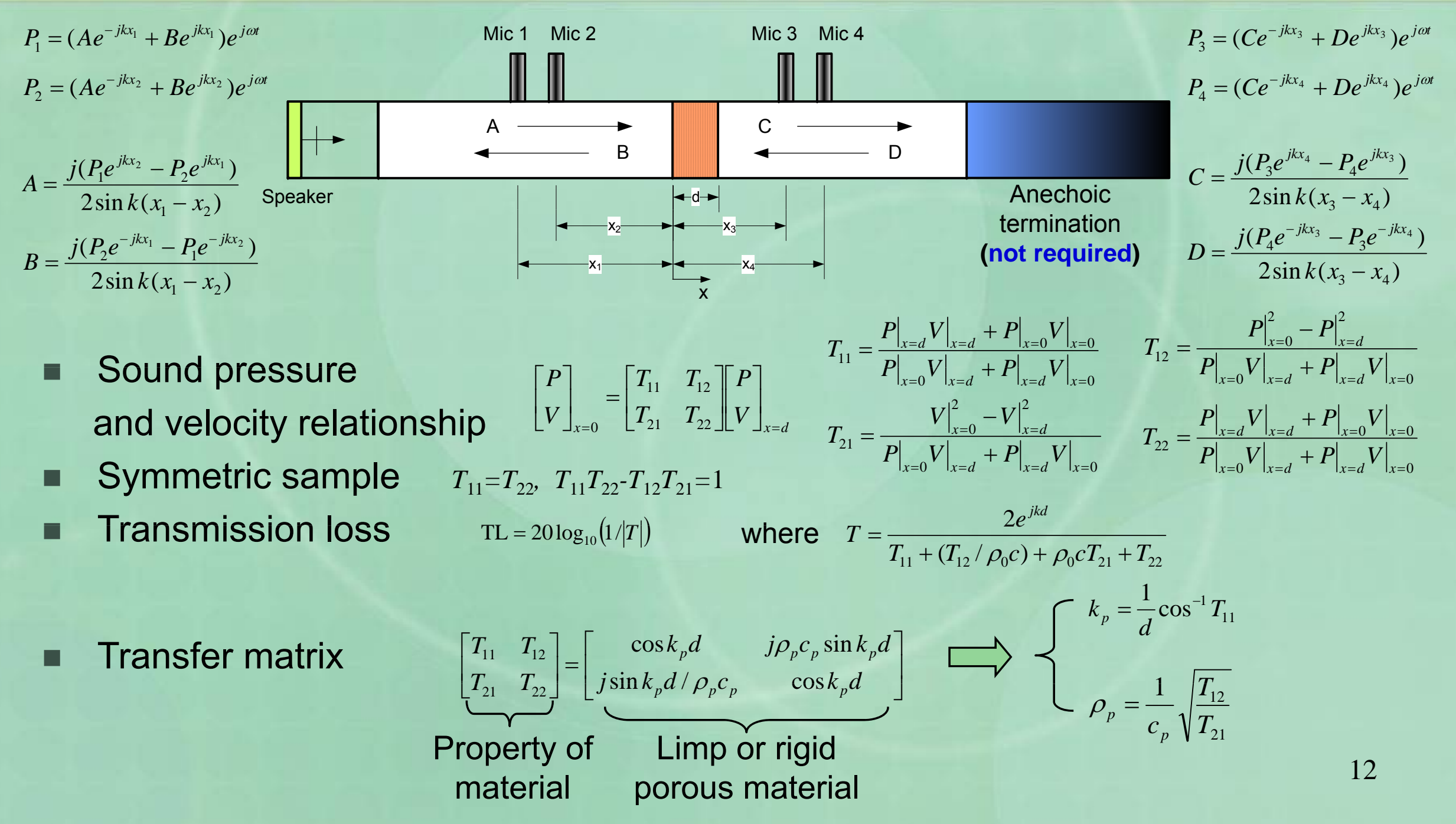




\section{Anechoic Transmission Loss}

Aviation grade glass fiber (density $=9.6 \mathrm{~kg} / \mathrm{m}^{3}$, flow resistivity= 31000 Rayls $/ \mathrm{m}$ )

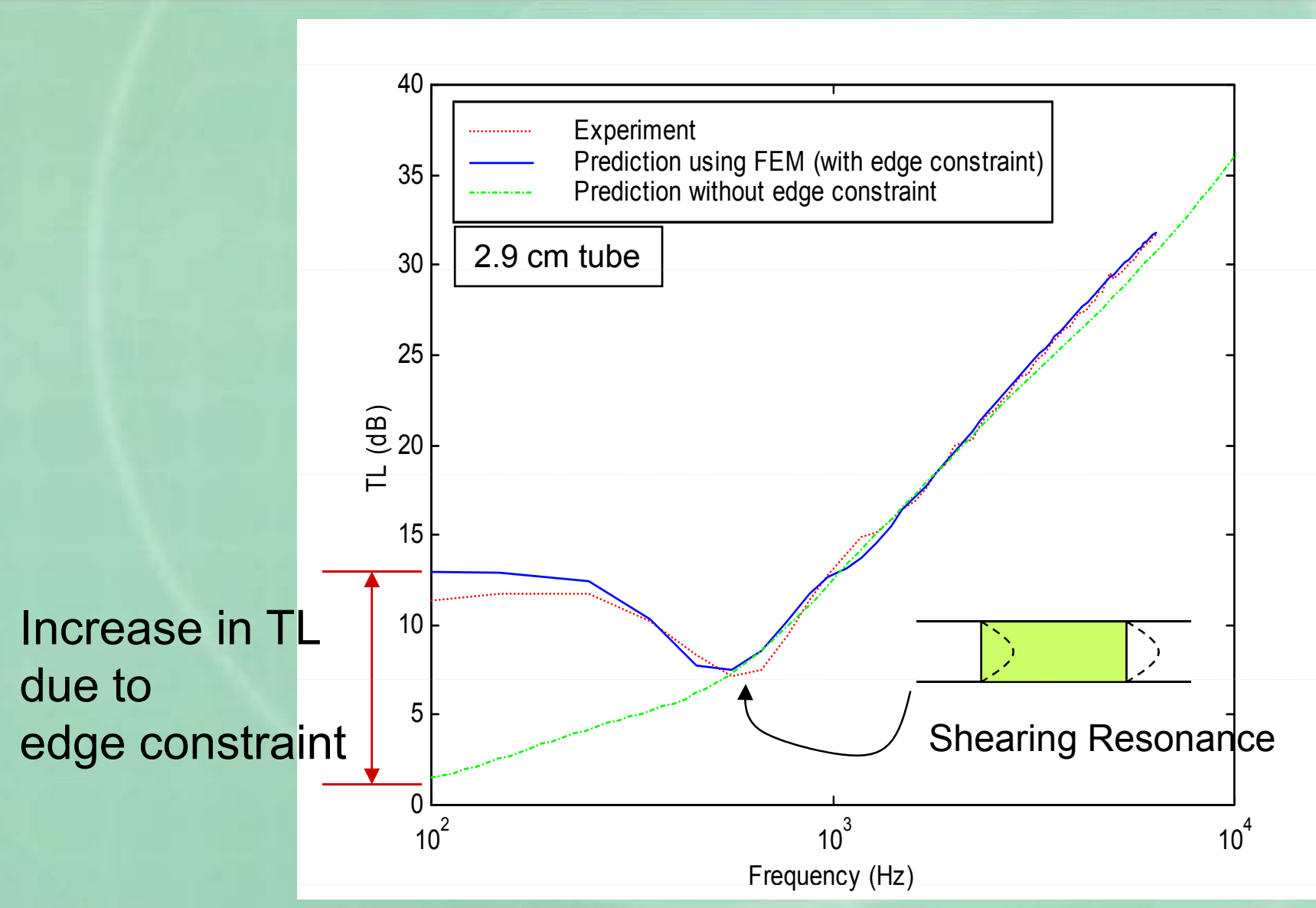

Above shearing resonance - finite size sample represents infinite sample

Below shearing resonance - all properties affected by edge-constraint 


\section{Estimation of Biot Parameters}

- Software available to estimate Biot parameters by performing optimal fit to measured acoustical data (flow resistivity, porosity, tortuosity, viscous characteristic length, thermal characteristic length, bulk density, Young's modulus, loss factor, Poisson ratio)

- ESI-FOAM-X (rigid, limp)

- COMET/Trim (rigid, limp, elastic)

- Original software based on transversely infinite layered representation: i.e., edge constraint effects are not included 


\section{Infinite Panel Model: COMET/TRIM}

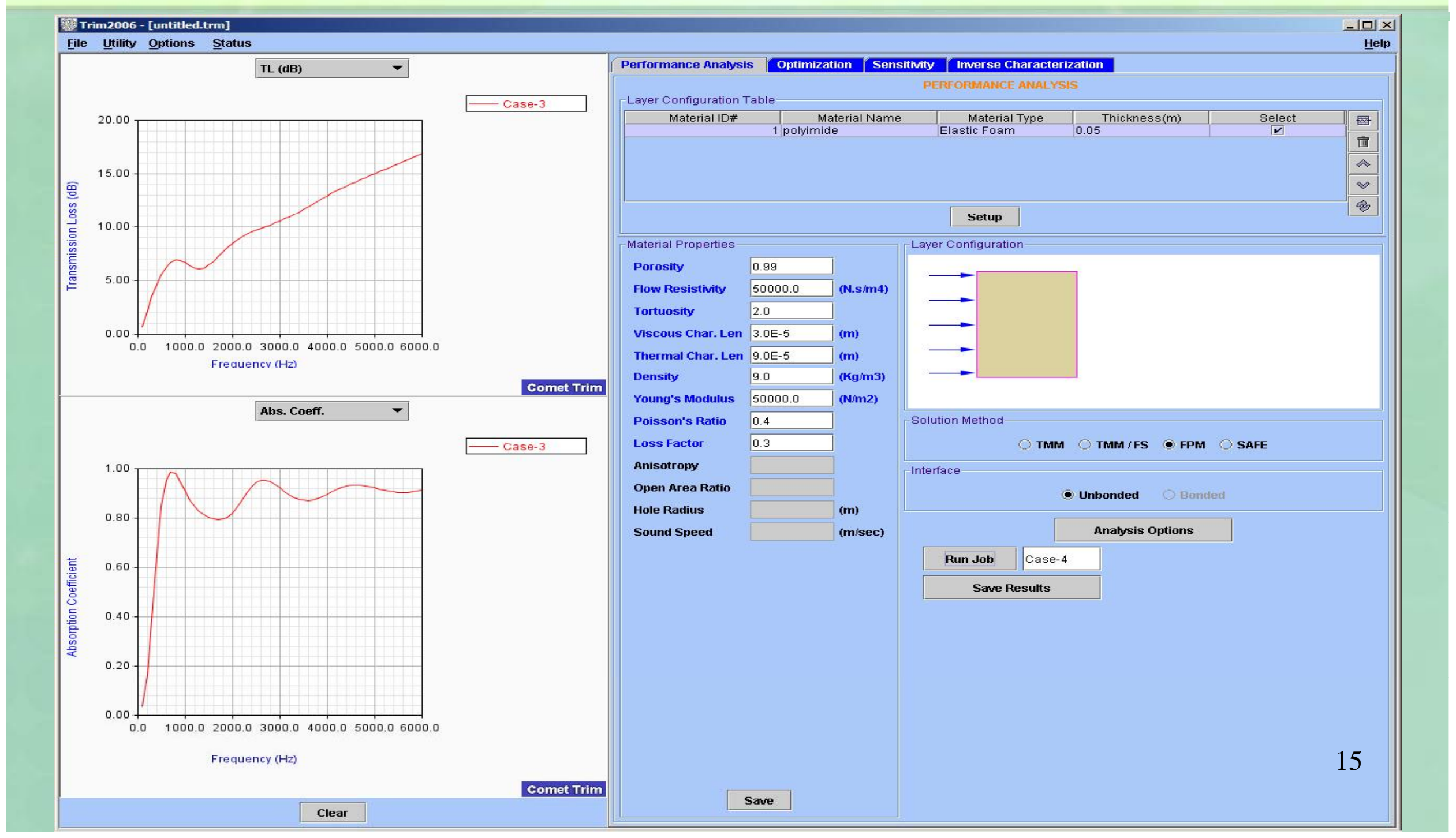




\section{Infinite Panel Model: Limitation}
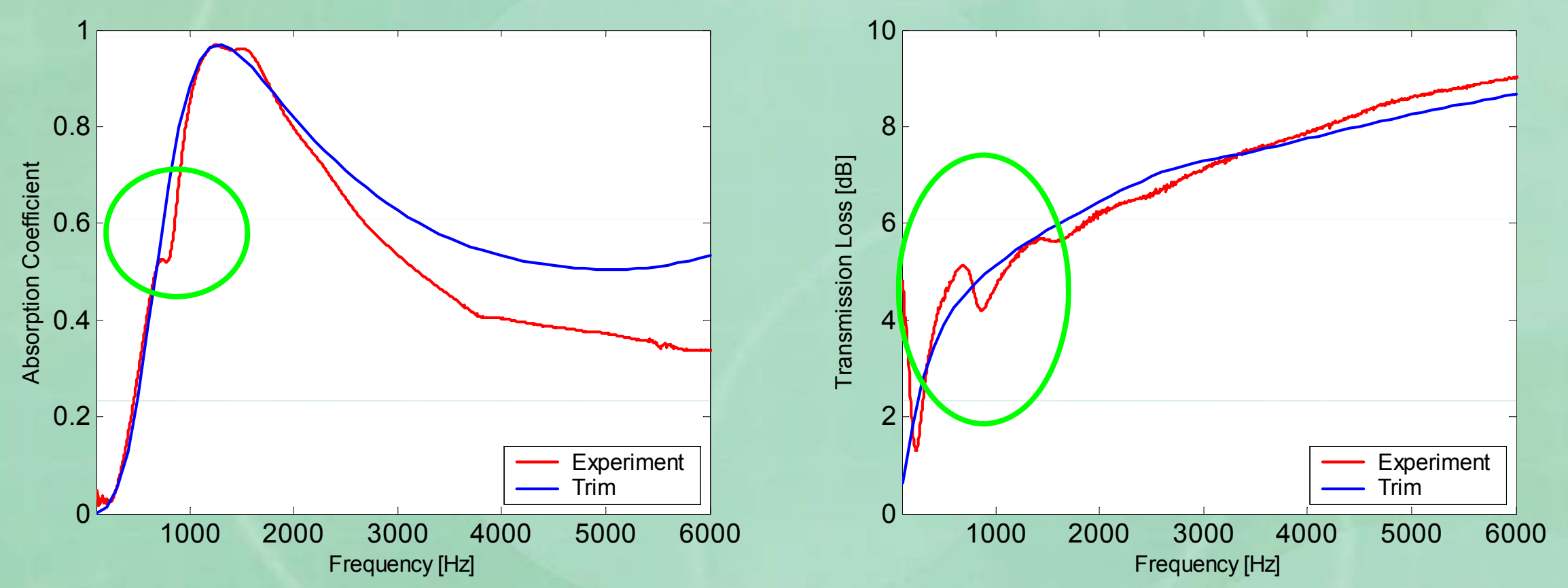

Note that this model does not simulate the low frequency transmission loss fluctuation caused by shearing resonance of the sample 


\section{Finite Element Models: COMET/SAFE}

- The software COMET/SAFE is used to model and compute the absorption and transmission loss having a finite depth and finite size layer of porous material.

- A finite element based program that allows for the analysis of sound traveling through various media including fluids, solids and foam-like substances.

- Finite element implementation is based on $u-U$ and $p-U$ versions of Biot theory.

- All models used in this work involved axisymmetric elements.

- The new version of TRIM supports automated inverse characterization capability based on SAFE. 


\section{Finite Element Model}
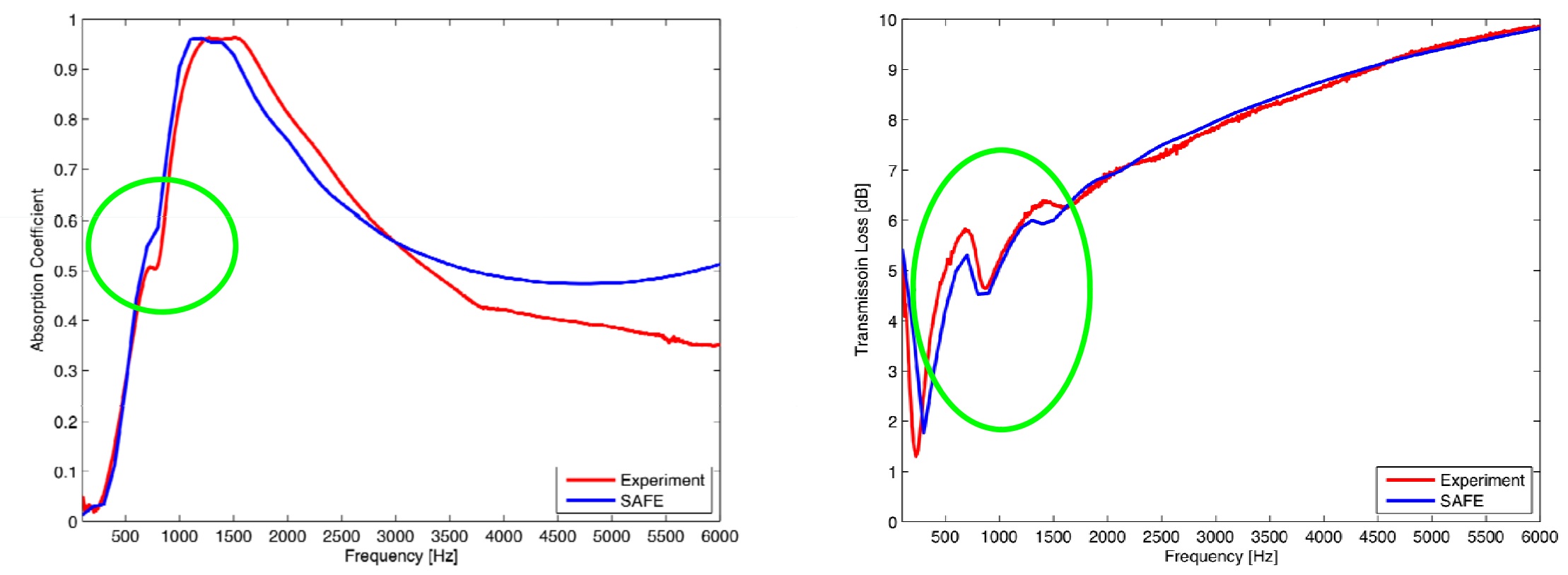

Note that finite model can simulate the low frequency transmission loss fluctuation caused by shearing resonance of the sample 


\section{Inverse Characterization}

- Questions: Is it possible to determine the Biot parameters from acoustical measurements? Do parameters act independently? How many parameters can be estimated?

- To help answer these questions, introduce a procedure based on Singular Value Decomposition

- Singular Value Decomposition is widely used linear algebraic method to identify the principal components in the field of image processing and signal processing. 


\section{Sensitivity Matrix Analysis Procedures}

1. Linearize absorption and transmission coefficient close to a certain parameter set

2. Use absorption and/or transmission coefficient values for certain number of frequencies to construct a sensitivity matrix

3. Perform singular value decomposition on the sensitivity matrix and extract singular values to determine effective rank (number of independent parameters)

4. Calculate condition number (the smaller the better) 


\section{Sensitivity Matrix Analysis}

- Linearize the expression for the absorption and transmission coefficient in the vicinity of a certain parameter set

For 1 frequency

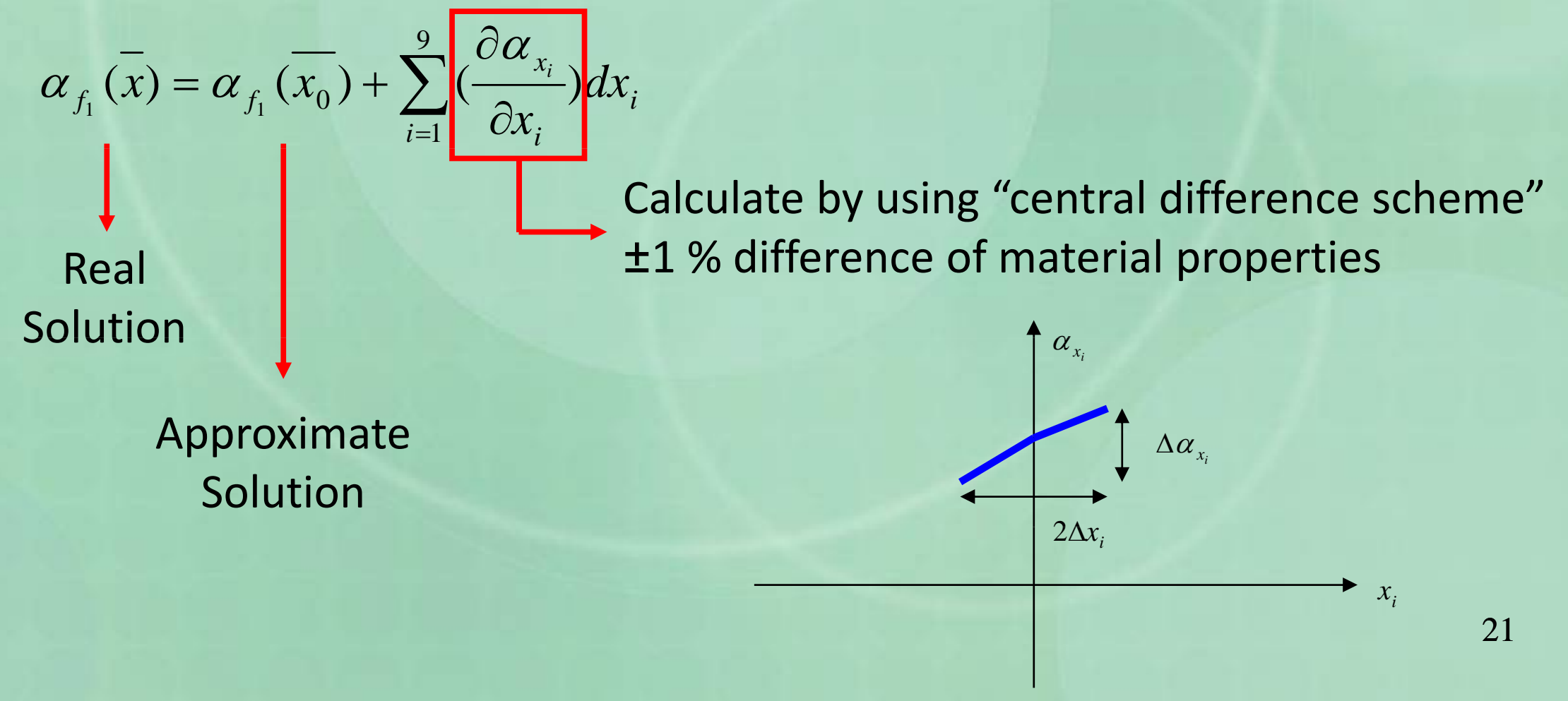




\section{Sensitivity Matrix Analysis}

For $\mathrm{n}$ frequencies, the equation can be combined as a matrix

$$
\left[\begin{array}{c}
\alpha_{f_{1}}(\bar{x}) \\
\cdots \\
\alpha_{f_{n}}(\bar{x})
\end{array}\right]=\left[\begin{array}{c}
\alpha_{f_{1}}\left(\overline{x_{0}}\right) \\
\cdots \\
\alpha_{f_{n}}\left(\overline{x_{0}}\right)
\end{array}\right]+\underbrace{\left.\begin{array}{cccc}
\frac{\partial \alpha_{f_{1} x_{1}}}{\partial x_{1}} & \frac{\partial \alpha_{f_{1} x_{2}}}{\partial x_{2}} & \ldots & \frac{\partial \alpha_{f_{1} x_{9}}}{\partial x_{9}} \\
\ldots & \ldots & \ldots & \ldots \\
\frac{\partial \alpha_{f_{n} x_{1}}}{\partial x_{1}} & \frac{\partial \alpha_{f_{n} x_{2}}}{\partial x_{2}} & \cdots & \frac{\partial \alpha_{f_{n} x_{9}}}{\partial x_{9}}
\end{array}\right]}\left[\begin{array}{c}
d x_{1} \\
\ldots \\
d x_{9}
\end{array}\right]
$$

Sensitivity Matrix

Perform singular value decomposition:

$\mathrm{M}=\mathrm{U} \Sigma \mathrm{V}^{*}$

The rank of the matrix $M$ equals the number of non-zero singular values which is the same as the number of non zero elements in the matrix $\Sigma$. 


\section{Rigid Foam Sensitivity Matrix Analysis}

- Use COMET/TRIM rigid foam type material that has 5 material properties. E.g., Porosity, flow resistivity, tortuosity, viscous and thermal characteristic length.

- The nominal values of the material properties are
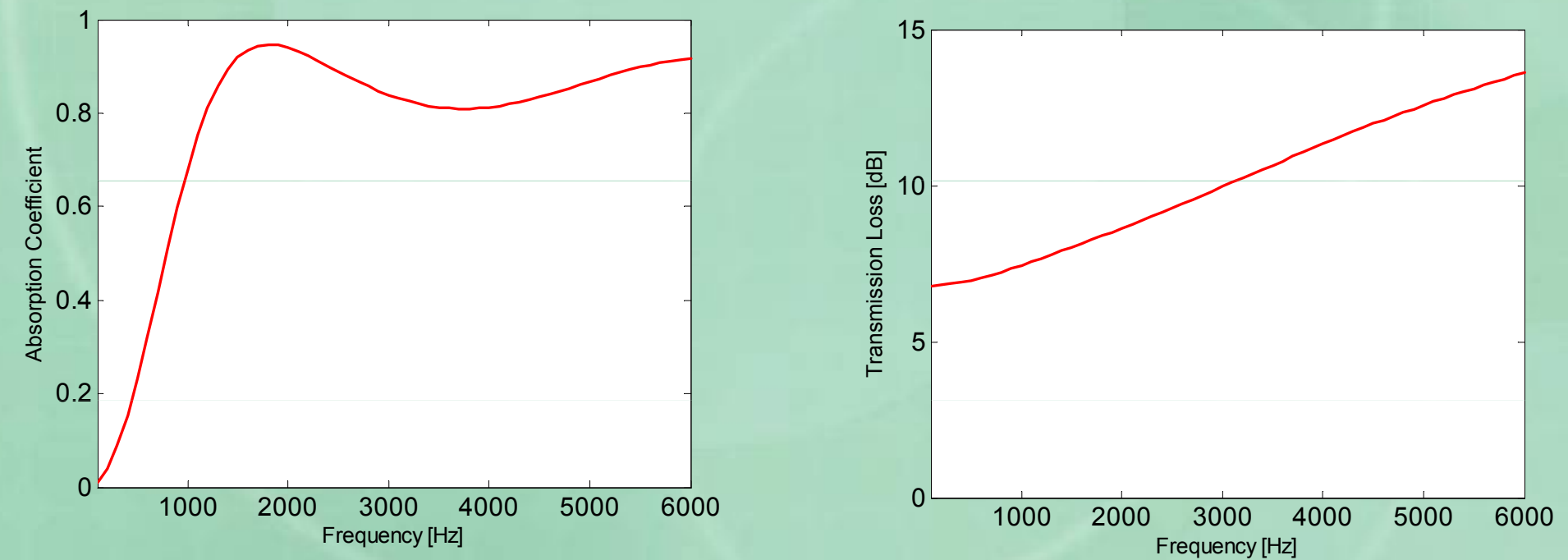

\begin{tabular}{|c|c|c|c|c|}
\hline Porosity & $\begin{array}{c}\text { Flow } \\
\text { Resistivity }\end{array}$ & Tortuosity & VCL & TCL \\
\hline 0.98 & 50,000 & 2.0 & $3.0^{*} 10^{-5}$ & $9.0^{*} 10^{-5}$ \\
\hline
\end{tabular}




\section{Rigid Foam Sensitivity Matrix Analysis}

- Effect of adding frequency data for absorption coefficient
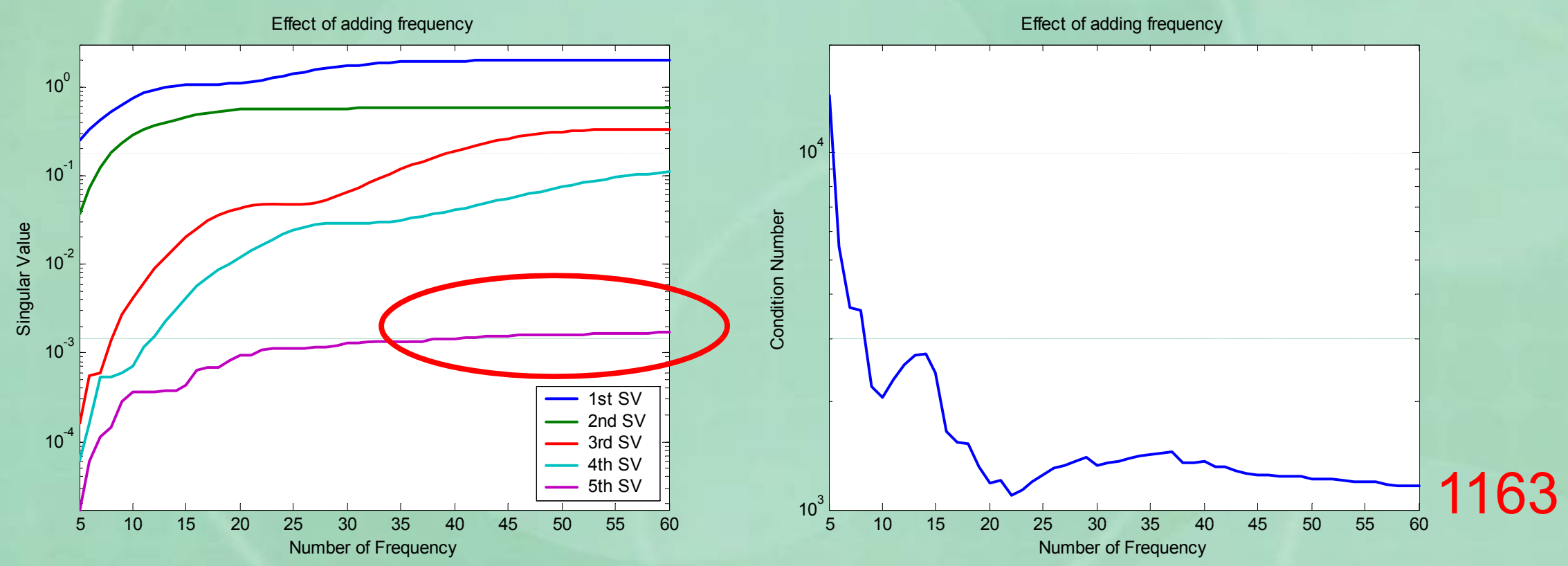

Adding additional frequency data reduces the condition number, but the condition number is too big to consider that the sensitivity matrix is well-posed. 


\section{Rigid Foam Sensitivity Matrix Analysis}

- Effect of adding frequency data for transmission coefficient
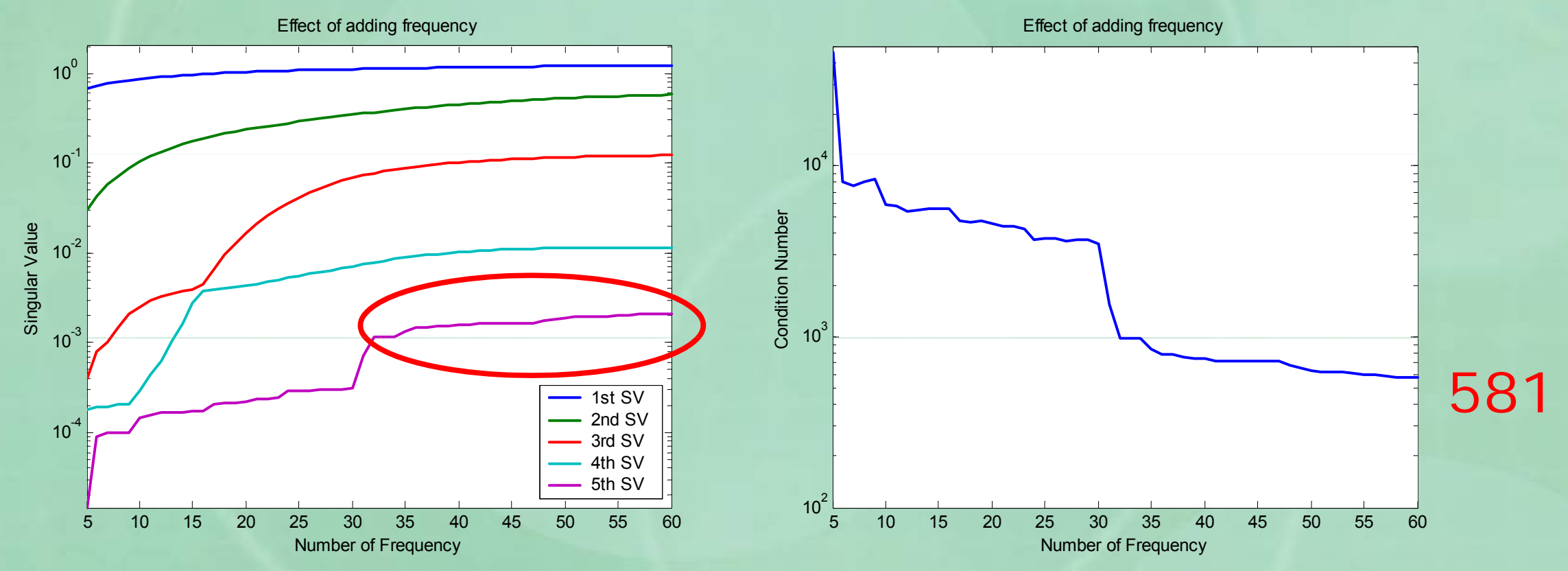

Adding additional frequency data reduces the condition number, but the condition number is too big to consider that the sensitivity matrix is well-posed. 


\section{Rigid Foam Sensitivity Matrix Analysis}

- Sensitivity matrix
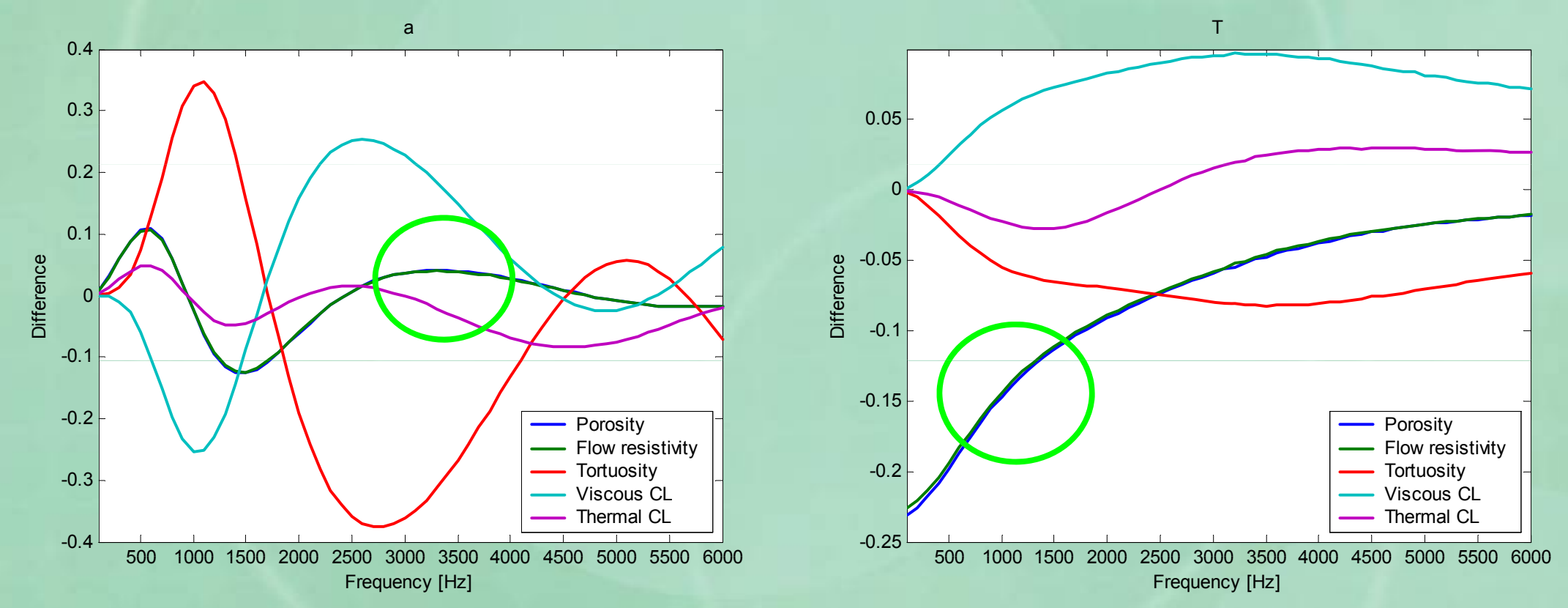

Sensitivities to porosity and flow resistivity are quite close to each other for both absorption and transmission coefficients 


\section{Singular Vector Absorption Coefficient}
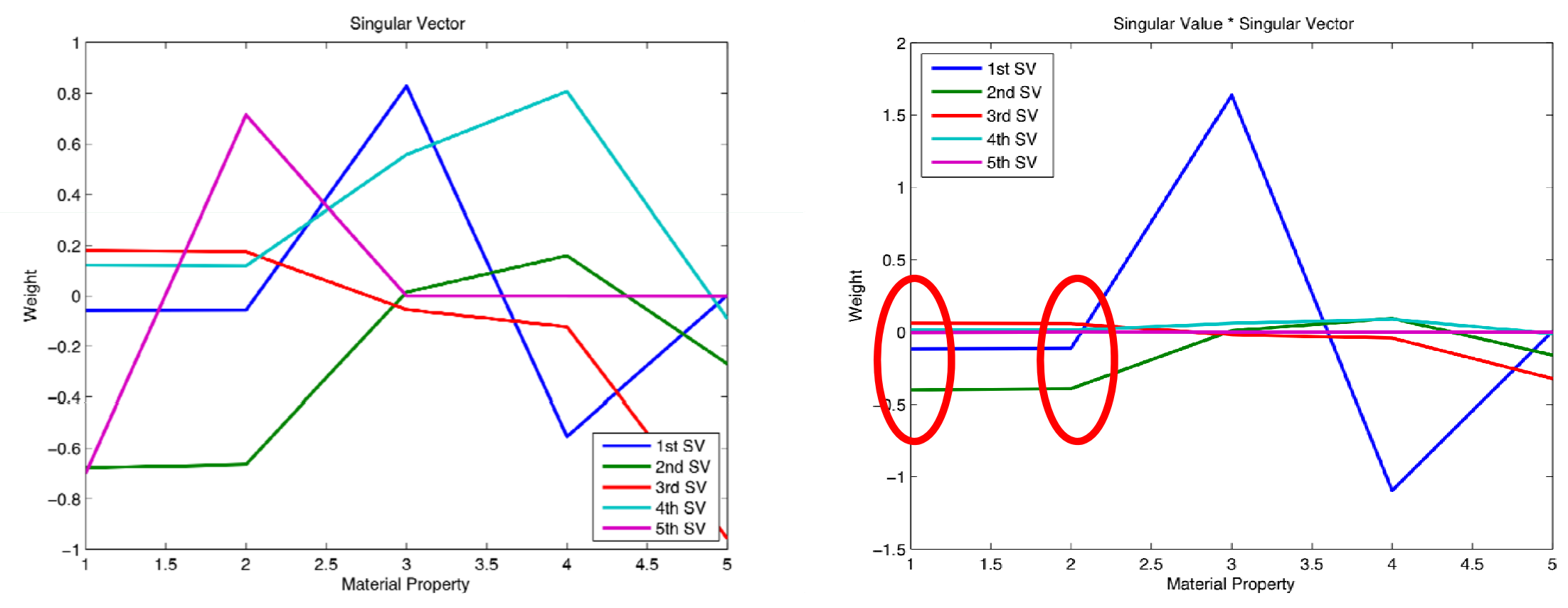

Note: Effect of material property 1 (porosity) and 2(flow resistivity) is almost the same on all five singular vectors. 


\section{Rigid Foam Sensitivity Matrix Analysis}

- Fixed porosity case result for absorption coefficient
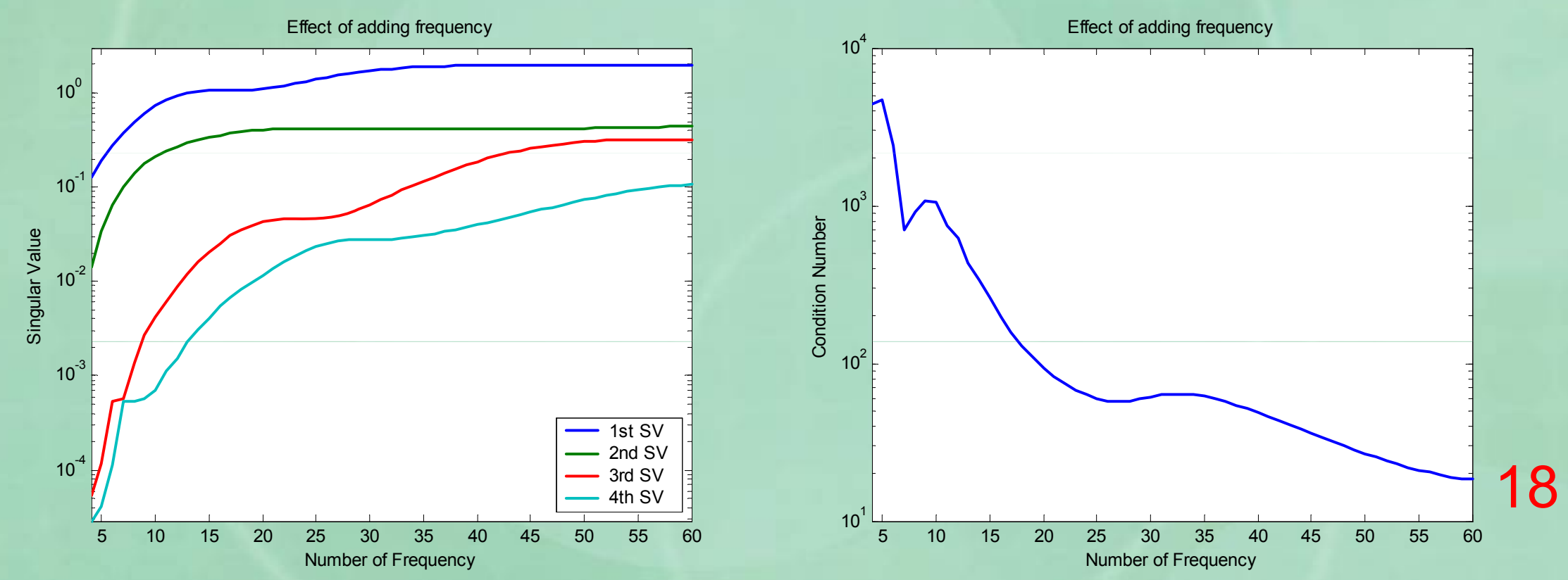

Fixing porosity reduces the condition number significantly and makes the sensitivity matrix well-posed. 


\title{
Rigid Foam Sensitivity Matrix Analysis
}

- Combine both absorption and transmission coefficient sensitivity matrix

\author{
Singular Value Condition Number \\ 2.1197 \\ 0.87038 \\ 11 \\ 0.39976 \\ 0.18173
}

Adding other acoustical measurements reduces the condition number further 


\section{Rigid Foam Sensitivity Matrix Analysis}

- To verify the effect of low and high condition number during the automatic inverse characterization in COMET/TRIM, two different cases were studied

\begin{tabular}{|c|c|c|c|c|}
\hline & Solution & $\begin{array}{c}\text { Initial } \\
\text { value }\end{array}$ & $\begin{array}{c}\text { Found } \\
\text { value 1 }\end{array}$ & $\begin{array}{c}\text { Found } \\
\text { value 2 }\end{array}$ \\
\hline Porosity & 0.98 & 0.5 & 0.54 & 0.98 \\
\hline Flow resistivity & 50,000 & 125,000 & 165,000 & 51,050 \\
\hline Tortuosity & 2.0 & 6.0 & 1.47 & 2.073 \\
\hline Viscous C.L & $3.0^{*} 10^{-5}$ & $9.0^{*} 10^{-5}$ & $1.77 * 10^{-5}$ & $3.08^{*} 10^{-5}$ \\
\hline Thermal C.L & $9.0^{*} 10^{-5}$ & $2.7 * 10^{-4}$ & $7.85 * 10^{-4}$ & $9.06^{*} 10^{-5}$ \\
\hline
\end{tabular}




\section{Optimal Inverse Characterization}

- 4 parameter search gives near optimal result
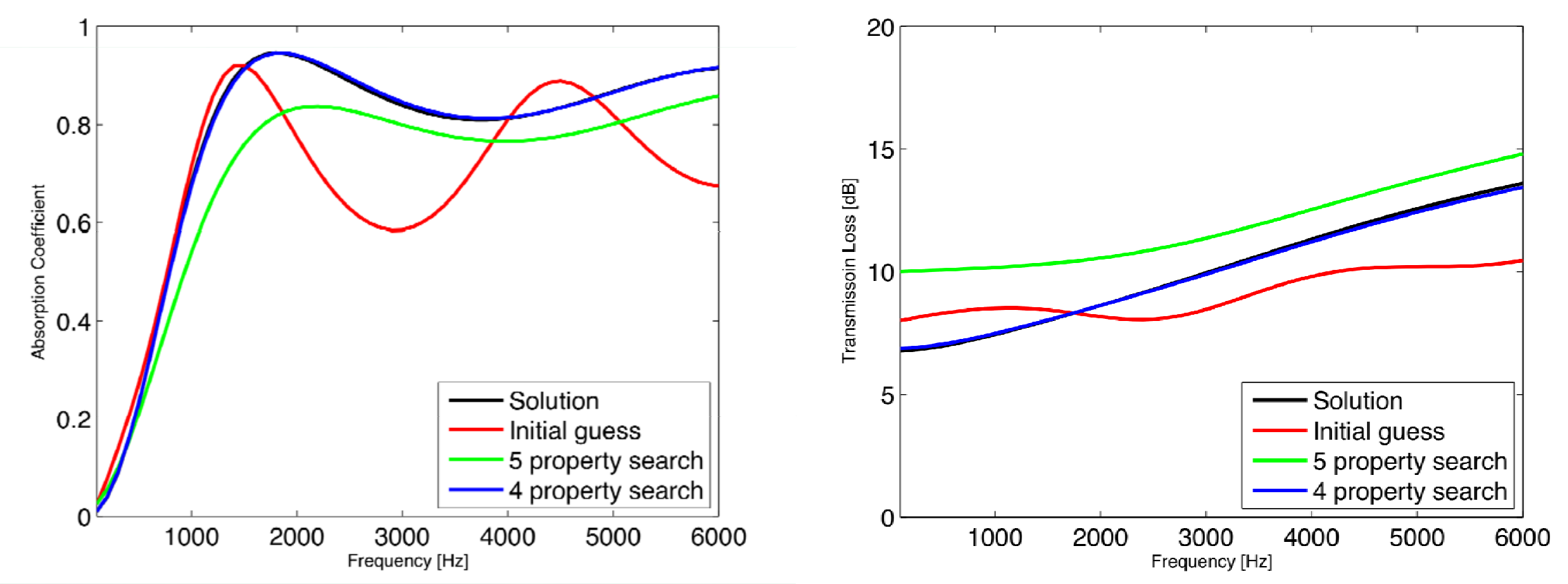


\section{Inverse Characterization based on FEM}

- Use COMET/SAFE (FEM) elastic foam type material that has 9 material properties listed below.

- Layer thickness $=5 \mathrm{~cm}$, Sample is fixed around circumferential edge
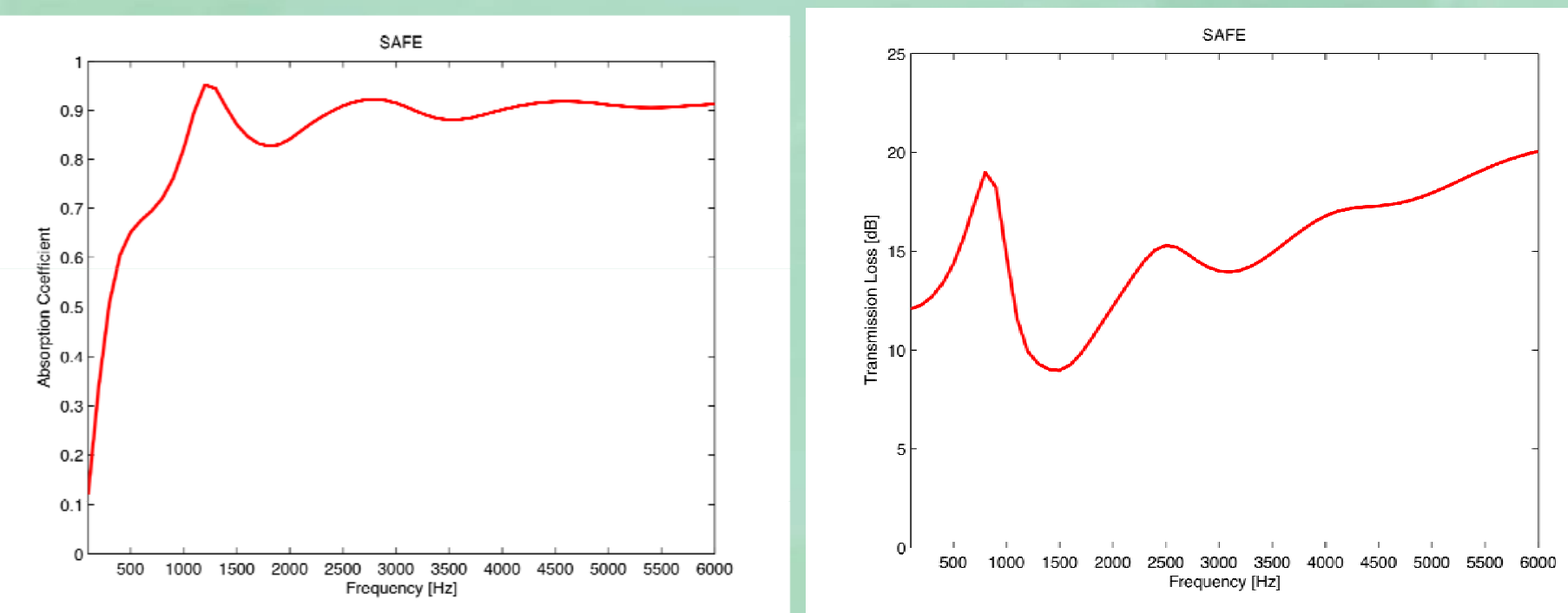

\begin{tabular}{|c|c|c|c|c|c|c|c|c|}
\hline Porosity & $\begin{array}{c}\text { Flow } \\
\text { Resistivity }\end{array}$ & Tortuosity & VCL & TCL & Density & $\begin{array}{c}\text { Young's } \\
\text { modulus }\end{array}$ & $\begin{array}{c}\text { Poisson's } \\
\text { ratio }\end{array}$ & $\begin{array}{c}\text { Loss } \\
\text { factor }\end{array}$ \\
\hline 0.98 & 50,000 & 2.0 & $3.0 * 10^{-5}$ & $9.0^{*} 10^{-5}$ & 9.0 & 50,000 & 0.4 & 632 \\
\hline
\end{tabular}




\section{Singular Vectors for Absorption and Transmission}

- Higher order singular vectors for absorption \& transmission coefficient case
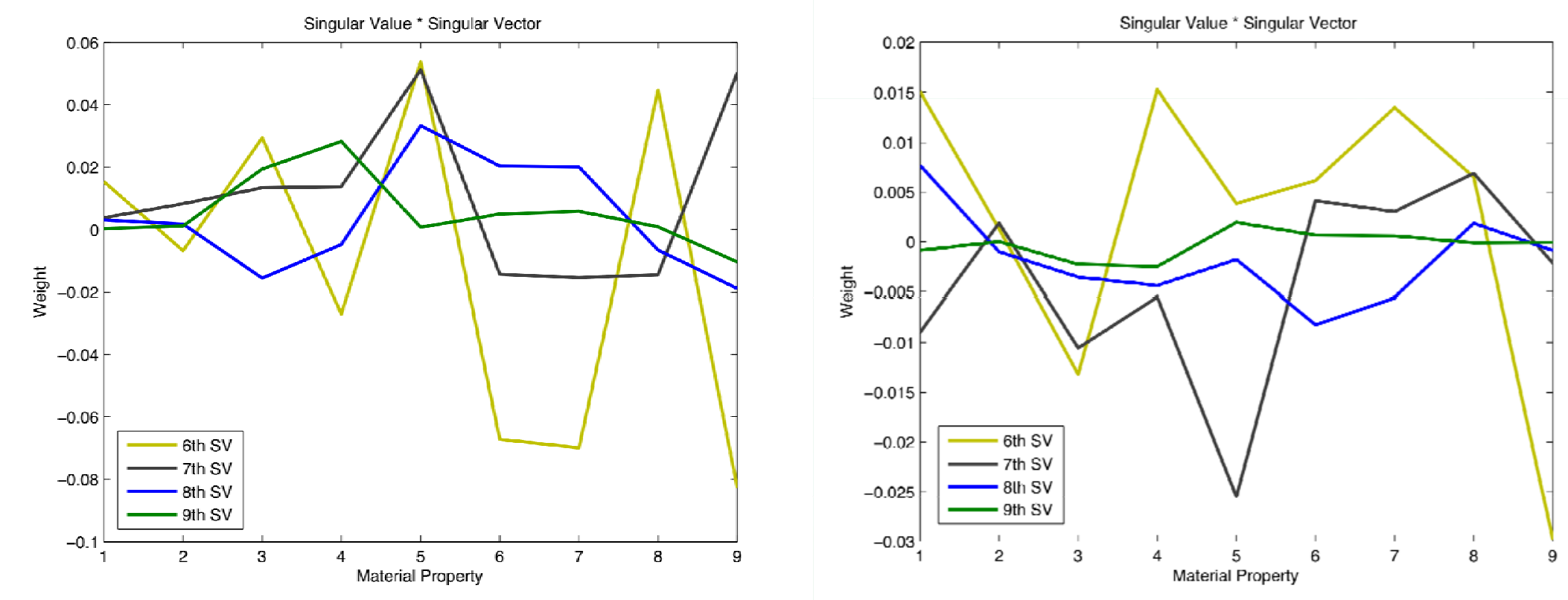

Even higher $\left(6^{\text {th }}, 7^{\text {th }}, 8^{\text {th }}\right.$, and $\left.9^{\text {th }}\right)$ order singular vectors have wide range of values - all parameters independent ${ }_{33}$ 


\section{Inverse Characterization Results}

\begin{tabular}{|c|c|c|c|}
\hline & Solution & Initial guess & Unfixed \\
\hline Porosity & 0.98 & 0.75 & 0.88 \\
\hline Flow resistivity & 50,000 & 45,000 & 51,203 \\
\hline Tortuosity & 2.0 & 1.7 & 2.04 \\
\hline Viscous C.L & $3.0^{*} 10^{-5}$ & $3.5^{*} 10^{-5}$ & $3.16^{*} 10^{-5}$ \\
\hline Thermal C.L & $9.0^{*} 10^{-5}$ & $1.05^{*} 10^{-4}$ & $8.66^{*} 10^{-5}$ \\
\hline Density & 9.0 & 7.5 & 9.87 \\
\hline Young's modulus & 50,000 & 45,000 & 53,445 \\
\hline Poisson's ratio & 0.4 & 0.35 & 0.399 \\
\hline Loss factor & 0.3 & 0.25 & 0.302 \\
\hline
\end{tabular}

- 9 parameters estimated with reasonable accuracy 


\section{Inverse Characterization Results}
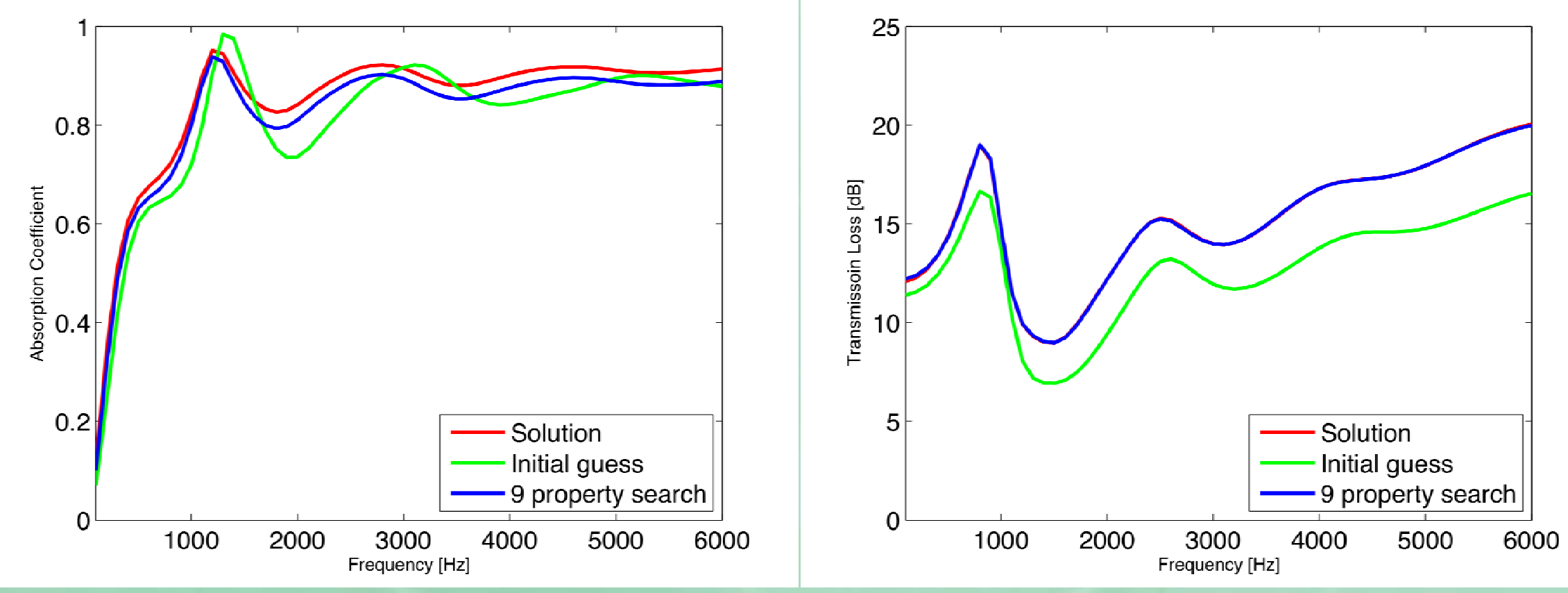


\section{Inverse Procedure based on FEM}

- The finite element model's condition number is significantly smaller than the condition number based on the plane wave model.

$$
\begin{aligned}
\text { Absorption coefficient: } 2336 & \rightarrow 49 \\
\text { Transmission coefficient: } 1309 & \rightarrow 178
\end{aligned}
$$

- This result is due to the fact that the finite element model can simulate finite sample size effects such as low frequency shearing resonance of the sample inside the tube.

- Therefore, the inverse characterizations based on the finite element model have better chance to extract correct material properties. 


\section{Conclusions}

- Standing wave tubes can provide both absorption and transmission loss data for estimation of Biot parameters by inverse methods, but edge constraint effects have a significant impact on the results

- By using a linearization and SVD procedure, the stability of the inverse process can be improved by removing material properties that makes the sensitivity matrix ill-conditioned.

- Inverse procedures based on finite element models of edgeconstrained samples may offer improved performance by making the effect of input parameters more independent 


\section{Acknowledgments}

- P. E. Doak

- Joe Pope

- L\&L Products

- United Technologies Research Center

- 3M Corporation (Jon Alexander)

- Bruel \& Kjaer (Oliviero Olivieri, Jason Kunio, Jorgen Hald)

- NASA (Richard Silcox)

- Richard Yun, Heuk Jin (Bryan) Song, Jinho Song, Jeong-woo Kim, Taewook Yoo, Kwanwoo Hong, Kang $\mathrm{Hou}$

- Tanya Wulf 